Article

\title{
Influence of Branching Density in Ethylene-Octene Copolymers on Electron Beam Crosslinkability
}

\author{
Petr Svoboda
}

Received: 11 November 2015; Accepted: 26 November 2015; Published: 2 December 2015

Academic Editor: Seth Darling

Department of Polymer Engineering, Faculty of Technology, Tomas Bata University in Zlin, Vavreckova 275, 76272 Zlin, Czech Republic; svoboda@ft.utb.cz; Tel.: +420-576-031-335; Fax: +420-577-210-172

\begin{abstract}
Two ethylene-octene copolymers (EOC) with the same melt flow index (MFI $=3 \mathrm{~g} / 10 \mathrm{~min}$ ) but different octene contents, being 20 and 35 wt \% (EOC-20 and EOC-35), were compared with regard to sensitivity to electron beam crosslinking. Dynamic mechanical analysis (DMA) revealed a large influence of the octene content on the storage modulus and the glass transition temperature $\left(T_{\mathrm{g}}\right)$ but a smaller influence of irradiation on the properties below melting point $\left(T_{\mathrm{m}}\right)$. Rheology at $150{ }^{\circ} \mathrm{C}$ pointed out large differences in samples crosslinked in the 0-60 kGy range and at lower frequencies $(0.1-1 \mathrm{~Hz})$. The loss factor $\tan \delta$ confirmed that before irradiation the two copolymers were very similar, while after irradiation to $120 \mathrm{kGy}$, the EOC-35 had considerably lower $\tan \delta$ than EOC-20, which corresponds to a better elasticity (or a higher level of crosslinking). A high-temperature creep test showed a considerably lower creep for EOC with a higher octene content. An analysis of the insoluble gel content exhibited higher values for EOC-35 confirming a higher level of crosslinking. Analysis according to the Charlesby-Pinner equation revealed increased crosslinking-to-scission ratio, $G(X) / G(S)$, for EOC-35. While the $G(X)$ value changed only slightly, a significant decrease in the $G(S)$ value was discovered.
\end{abstract}

Keywords: ethylene-octene copolymer; electron beam irradiation; crosslinking; rheology; creep

\section{Introduction}

The development of catalysts has led to a new class of polyolefin copolymers [1]. The older type of polyolefins produced by Ziegler-Natta catalysts had a broad molecular weight distribution (MWD) and a broad distribution of the comonomer. The new type of copolymer is produced by constrained geometry catalyst technology (CGCT), which leads to copolymers with a narrow MWD and also a very uniform comonomer distribution; in other words, a uniform short chain branching (SCB). Processability (shear thinning) is enhanced by a controlled level of long chain branching (LCB).

These copolymers provide an excellent opportunity to study structure-property relationships as a function of only one variable while all other variables are kept constant. This is a necessary condition for obtaining meaningful results. Alamo et al. studied the influence of comonomer type (butane, hexane, octene) and also the influence of molecular weight [2]. Bensason et al. studied the influence of comonomer content [3], and Wood-Adams et al. focused on the degree of LCB [4].

Ethylene-octene copolymers with densities smaller than $0.89 \mathrm{~g} / \mathrm{cm}^{3}$ have no lamellae or spherulites. Fringed micellar or bundled crystals are inferred from a low degree of crystallinity, a low melting temperature, and a granular nonlamellar morphology [5]. This unique crystalline structure then influences the mechanical properties. During the tensile test, the yield point is not present and the elastic behaviour is greatly improved (measured by tremendously reduced permanent set after repeated elongation to $100 \%$ ) [1]. 
Ethylene-octene copolymers (EOC) have many other desirable properties, including softness, long shelf life, and good tear resistance, which enable various applications. These applications include elastic fibres for apparel with improved UV resistance (to replace Elastane) [6], packaging, blood bags, and catheters in hospitals [7]. Crosslinked polyolefin foams have various kinds of applications, such as thermal insulation, floatation, automotive trim, and sporting goods $[8,9]$. For some applications it is necessary to crosslink these new elastic polyolefins because some of them have a very low melting point (in the range of $45-55^{\circ} \mathrm{C}$ ) [10].

There are several possibilities of how to crosslink saturated polyolefin. One possibility is careful mixing with peroxide (the temperature must be kept low to avoid premature crosslinking during mixing) followed by high-temperature crosslinking of the moulded article [8,11]. Another method includes grafting by vinyltrimethoxy silane followed by exposure to water or humidity at elevated temperatures [12-26]. Last but not least is crosslinking by electron $[11,27,28]$ or gamma $[7,9,29]$ irradiation.

Although several researchers have attempted to compare the crosslinking behaviour of these copolymers, their research unfortunately varies several parameters at the same time (e.g., octene content and molecular weight) which leads to dubious conclusions. At present, there is no solid understanding of the effect of octene content on crosslinkability by irradiation. In order to get scientifically sound conclusions, in our studies we have attempted to have only one variable (octene content), while keeping all other parameters constant.

The main objective of this paper is to investigate of the influence of electron irradiation on the crosslinking behaviour of ethylene-octene copolymers with the same initial melt flow index but with a different octene content. While the introduction of peroxide or silane could cause some inhomogeneities, and thus influence the results, the e-beam crosslinking method represents a very pure, smart, and modern way of 3D network formation-for this reason, it was chosen for this investigation. It must be mentioned that the level of crosslinking was kept rather low compared to crosslinking levels in tyres, for example. This lower level of crosslinking is industrially important, for example, during foaming when the level of crosslinking must not be too high (bubbles cannot grow) or too low (bubbles collapse during foaming) [8,9]. Testing methods included dynamic mechanical analysis (DMA), rheology, a high-temperature creep test, and an analysis of the gel content.

\section{Experimental}

\subsection{Materials}

Two ethylene-octene copolymers with the trade name ENGAGE ${ }^{\circledR}$ and supplied by The Dow Chemical Company (Midland, MI, USA) which had different octene contents but the same initial melt flow index (MFI), being $3 \mathrm{~g} / 10 \mathrm{~min}$ at $190{ }^{\circ} \mathrm{C}$, were chosen. The octene contents of these copolymers were 20 and $35 \mathrm{wt} \%$. For a better understanding, the abbreviations EOC-20 and EOC-35 reflect the octene content in wt \%. The molecular weights were measured by gel permeation chromatography (GPC) and were found to be very similar for both samples. The octene content was also recalculated from wt $\%$ into mol $\%$, and so the ethylene-to-octene molar ratio was calculated (see Table 1). Based on this data, an ideal theoretical chemical structure is shown in Figure 1a. In reality the copolymer is random and therefore the real chemical structure looks slightly different. However, Figure 1 is useful for the illustration that EOC-35 has about two-times higher branching density than EOC-20. The difference is not negligible and one can make a significantly sound conclusion about the influence of the branching density on crosslinkability of these ethylene-octene copolymers. Figure $1 \mathrm{~b}$ illustrates the presence of both short chain branching (SCB) and also the controlled level of long chain branching (LCB), which tremendously influences processability (shear thinning) $[1,4]$. 
Low density polyethylene (LDPE), which has been used for a comparison of some properties, was Bralene RB 2-62, manufactured by Slovnaft Petrochemicals, Bratislava, Slovak Republic. MFI and the density of Bralene RB 2-62 was $2 \mathrm{~g} / 10 \mathrm{~min}$ and $0.918 \mathrm{~g} \cdot \mathrm{cm}^{-3}$, respectively.

Table 1. Composition, density, and molecular weight of investigated ethylene-octene copolymers (EOC). Melt flow index at $190^{\circ} \mathrm{C}$ was $3.0 \mathrm{~g} / 10 \mathrm{~min}$ for both samples.

\begin{tabular}{|c|c|c|c|c|c|c|c|c|c|c|}
\hline \multirow{2}{*}{ Sample } & \multirow{2}{*}{$\begin{array}{l}\text { Trade } \\
\text { Name }\end{array}$} & Octene & Ethylene & Octene & Ethylene & ET/OCT & Density & $M_{\mathrm{w}}$ & $M_{\mathrm{n}}$ & PDI \\
\hline & & wt $\%$ & wt $\%$ & mol \% & mol \% & Molar Ratio & $\mathrm{g} / \mathrm{cm}^{3}$ & $\mathrm{Da}$ & $\mathrm{Da}$ & - \\
\hline EOC-20 & $\begin{array}{c}\text { ENGAGE } \\
8450\end{array}$ & 20 & 80 & 5.88 & 94.12 & 16.0 & 0.902 & 78,540 & 37,400 & 2.10 \\
\hline EOC-35 & $\begin{array}{c}\text { ENGAGE } \\
8452\end{array}$ & 35 & 65 & 11.86 & 88.14 & 7.4 & 0.875 & 93,106 & 42,321 & 2.20 \\
\hline
\end{tabular}

(a)

EOC-20: 20 wt. \% of octene ethylene/octene molar ratio = 16:1 ENGAGE 8450

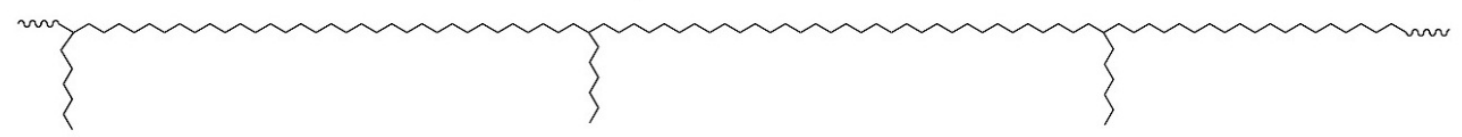

EOC-35: 35 wt. \% of octene ethylene/octene molar ratio $=7.4 / 1 \quad$ ENGAGE 8452
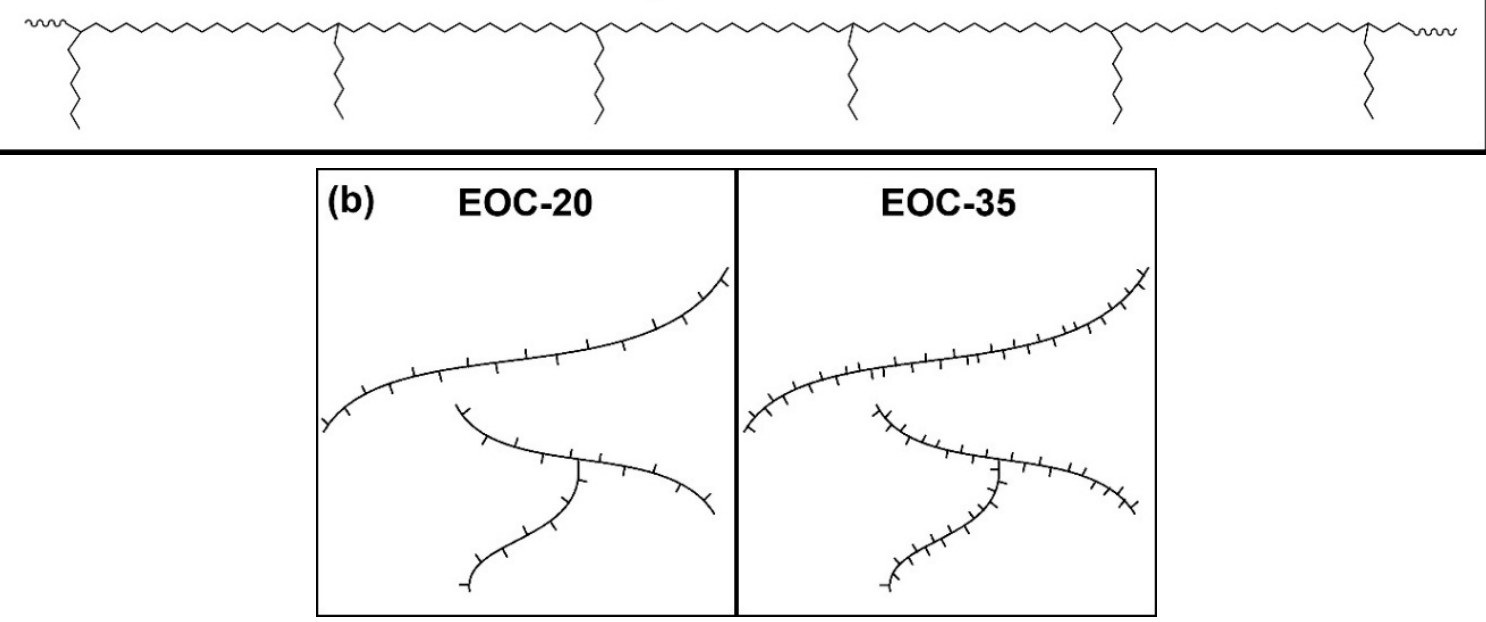

Figure 1. Schematics of investigated ethylene-octene copolymers: (a) ideal theoretical arrangement from the ethylene/octene molar ratio; (b) structures showing short and long chain branching (SCB and LCB).

\subsection{Compression Moulding of the Sheets}

Sheets with thickness $0.5 \mathrm{~mm}$ (stainless steel frame size was $12 \mathrm{~cm} \times 6 \mathrm{~cm}$ ) were prepared by compression moulding. Pellets were pre-heated at $130{ }^{\circ} \mathrm{C}$ under minimal pressure for $5 \mathrm{~min}$ and compressed at $10 \mathrm{MPa}$ for $3 \mathrm{~min}$ in a laboratory press, and then quenched in another cold press under pressure.

\subsection{Electron Beam Irradiation}

Electron irradiation was performed in normal air at room temperature, in BGS Beta-Gamma-Service $\mathrm{GmbH}$, Wiehl, Germany. The temperature was controlled not to exceed $50{ }^{\circ} \mathrm{C}$. The source of radiation was toroid electron accelerator Rhodotron $(10 \mathrm{MeV}, 200 \mathrm{~kW})$. The irradiation was carried out in a tunnel on a continuously moving conveyer with the irradiation dosage ranging from $30-120 \mathrm{kGy}$, in steps of $30 \mathrm{kGy}$ per pass. 


\subsection{Dynamic Mechanical Analysis (DMA)}

DMA was carried out in an IT Keisoku-seigyo (DVA-200S) machine (Osaka, Japan). Specimens were tested in the dynamic tensile mode with a frequency of $10 \mathrm{~Hz}$ and a strain of $0.1 \%$ from -100 to $+200{ }^{\circ} \mathrm{C}$ with a heating rate of $5 \mathrm{~K} \cdot \mathrm{min}^{-1}$ and a grip-to-grip distance of $13.0 \mathrm{~mm}$.

\subsection{Rheology}

Advanced Rheometric Expansion System ARES 2000 (Rheometric Scientific, Inc., Piscataway, NJ, USA) equipped with $25 \mathrm{~mm}$ parallel plates geometry was used to determine storage modulus $\mathrm{G}^{\prime}$, loss modulus $\mathrm{G}^{\prime \prime}$, and complex viscosity $\eta^{*}$ in the frequency range $0.1-100 \mathrm{rad} \cdot \mathrm{s}^{-1}$ at constant temperature $\left(150{ }^{\circ} \mathrm{C}\right)$ and strain $(1 \%) \cdot \tan \delta=\mathrm{G}^{\prime \prime} / \mathrm{G}^{\prime}$.

\subsection{High-Temperature Creep Test}

Tensile samples were cut out of the cross-linked sheets and were used for the tensile creep experiments according to ISO 899. Creep testing was carried out in a Memmert UFE 400 oven with digital temperature control. Creep was recorded through the glass window using a SONY SLT-A33 camera, capable of HD $1920 \times 1080$ video $(25$ frames/s). This video was later analysed at regular time intervals. The effects of octene content, MFI, and radiation dose on the creep behaviour of e-beam crosslinked EOC were studied at a fixed stress level of $0.1 \mathrm{MPa}$ and a temperature of $150^{\circ} \mathrm{C}$.

\subsection{Gel Content}

The gel content of the e-beam crosslinked EOC and LDPE samples were determined by an evaluation of the content of insoluble fraction of cross-linked material after solvent extraction, according to ASTM D2765-01. About $0.3 \mathrm{~g}$ of cross-linked sample was wrapped in a 120 mesh stainless steel cage and extracted in refluxing xylene containing $1 \mathrm{wt} \%$ of antioxidant (Irganox 1010) for $6 \mathrm{~h}$. The sample was then dried in a vacuum at $55^{\circ} \mathrm{C}$ and weighed. The gel content was calculated as a ratio of the final weight to the initial weight of the sample multiplied by one hundred. Always, three samples were averaged.

\subsection{Size-Exclusion Chromatography}

The molecular weight measurements were performed at $160{ }^{\circ} \mathrm{C}$ on a Polymer Laboratories PL 220 high-temperature chromatograph (Polymer Laboratories, Varian Inc., Church Stretton, Shropshire, England) equipped with three $300 \mathrm{~mm} \times 7.5 \mathrm{~mm}$ PLgel Olexis columns and a differential refractive index detector. 1,2,4-Trichlorobenzene (TCB) was used as an eluent, stabilized with butylhydroxytoluene (BHT) (Ciba, Basel, Switzerland) as an antioxidant. A mobile phase flow rate of $1 \mathrm{~mL} \cdot \mathrm{min}^{-1}$ was used and $200 \mu \mathrm{L}$ was injected in all cases. All samples were prepared to a concentration of $0.5 \mathrm{mg} \cdot \mathrm{mL}^{-1}$ in TCB. Narrowly distributed polyethylene standards (Polymer Standards Service $\mathrm{GmbH}$, Mainz, Germany) were used for calibration purposes.

\section{Results and Discussion}

Initially these two copolymers were investigated at lower temperatures by dynamic mechanical analysis (DMA). Figure 2a shows the storage modulus curves. Below $-50{ }^{\circ} \mathrm{C}$ there is a very small difference between these copolymers. Above $-50{ }^{\circ} \mathrm{C}$ the EOC-35 exhibits a much lower storage modulus at all temperatures. This is caused by a greater disruption of regularity in the ethylene chain, which leads to lower crystallinity.

Figure $2 \mathrm{~b}$ illustrates $\tan \delta$ curves. The EOC-35 shows a single peak at $-38{ }^{\circ} \mathrm{C}$ while EOC-20 exhibits two peaks, one at $-22{ }^{\circ} \mathrm{C}$, the other at $+40{ }^{\circ} \mathrm{C}$. They are called $\beta$ and $\alpha$ transitions. The relaxation behaviour of ethylene copolymers is strongly influenced by variables that describe the crystalline state, such as crystallinity, lamellar thickness, and interfacial structure. In literature [3], three relaxations were observed and identified conventionally as $\alpha, \beta$, and $\gamma$, in order of decreasing 
temperature for non-crosslinked copolymers. The low-temperature $\gamma$ relaxation (at around $-120{ }^{\circ} \mathrm{C}$ ) is the least sensitive to comonomer content; it is not shown in this paper. However, $\alpha$ and $\beta$ relaxations are strongly affected by comonomer content. $\beta$ relaxation (at -38 and $-22{ }^{\circ} \mathrm{C}$ ) relates to glass transition temperature $\left(T_{\mathrm{g}}\right)$, while $\alpha$ relaxation $\left(\mathrm{at}+40^{\circ} \mathrm{C}\right.$ ) relates to the reorganization of chain segments at crystal surfaces and the redistribution of tight and loose folds, cilia, and inter-crystalline links that make up the amorphous layer [3].
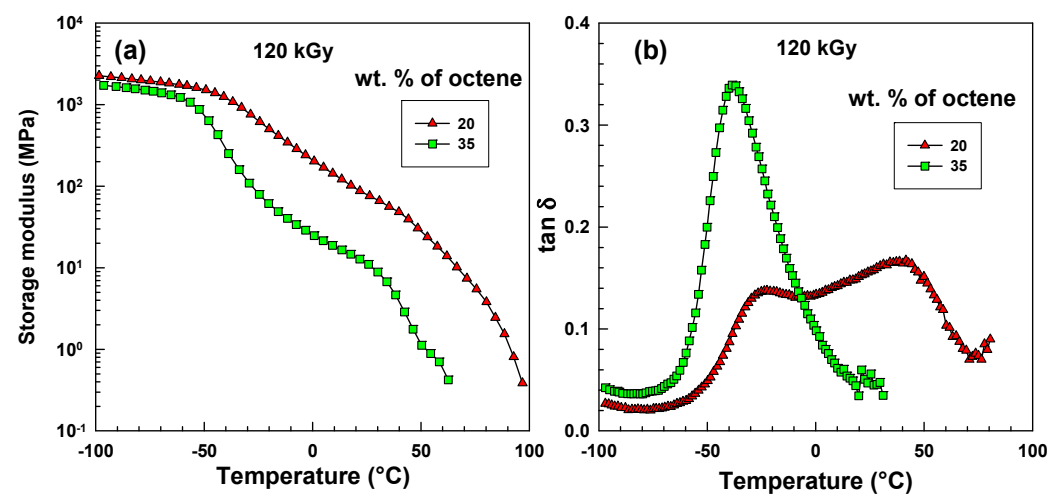

Figure 2. Dynamic mechanical analysis (DMA) results of crosslinked samples. (a) storage modulus; (b) loss factor $\tan \delta$.

Figure 2 illustrates results only for copolymers crosslinked by $120 \mathrm{kGy}$. The curves of polymers irradiated to a smaller extent looked very similar to these (so it is not necessary to show them all). Positions of the first peak were then used to see the influence of octene content and radiation level on glass transition temperature $\left(T_{\mathrm{g}}\right)$, which is illustrated in Figure 3a.
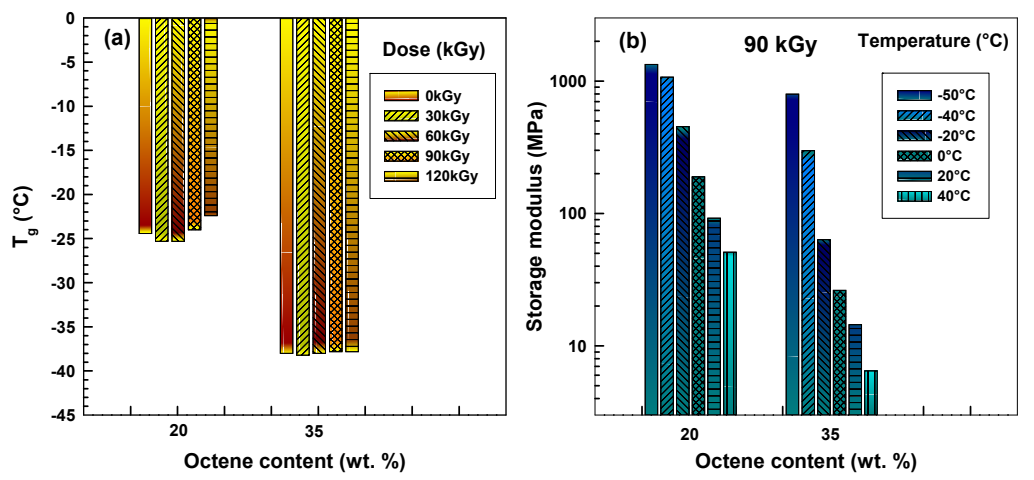

Figure 3. DMA analysis results. (a) $T_{\mathrm{g}}$ from peak positions of $\tan \delta$ in Figure $2 \mathrm{~b}$; (b) storage modulus at various temperatures from Figure $2 \mathrm{a}$.

Increasing the octene content decreases the $T_{\mathrm{g}}$ significantly. A lower $T_{\mathrm{g}}$ is favourable for impact toughness at low temperatures. Low-temperature impact testing is a common practice for consumer products that are dropped on the ground on a cold winter day, such as cell phones. Interestingly, the radiation does not significantly influence the $T_{\mathrm{g}}$. Below melting point $\left(T_{\mathrm{m}}\right)$, mechanical properties are governed mainly by crystals that hold amorphous chains together.

In contrast, the properties above $T_{\mathrm{m}}$ are greatly influenced by radiation levels when chemical bonds play an important role; this will be shown in the following sections. The DMA revealed important data about the influence of octene content on the storage modulus at various temperatures (see Figure 3b). Higher octene content causes a lower storage modulus (or higher softness) in a copolymer. The influence is large, therefore the storage modulus axis is in logarithmic scale. The difference was less pronounced at lower temperatures $\left(-50\right.$ and $\left.-40{ }^{\circ} \mathrm{C}\right)$. 
High-temperature testing, when all physical crosslinking (crystals holding amorphous chains) disappears and only chemical crosslink bonds caused by irradiation remain, reveals with a high sensitivity the differences among samples exposed to various levels of radiation.

The first of these high-temperature tests is rheological measurement at $150{ }^{\circ} \mathrm{C}$, as shown in Figure 4. $G^{\prime}, \eta^{*}$, and $\tan \delta$ values are plotted as a function of frequency. The $G^{\prime}$ and $\eta^{*}$ curves are systematically arranged with higher values for higher radiation levels at lower frequencies $\left(0.1-1 \mathrm{rad} \cdot \mathrm{s}^{-1}\right)$. At a lower frequency, the chemical crosslinking plays an important role, while at higher frequencies (10-100 rad.s $\mathrm{s}^{-1}$ ), the entanglements on the molecules play an important role in rheology data (the above-mentioned trend was not observed).

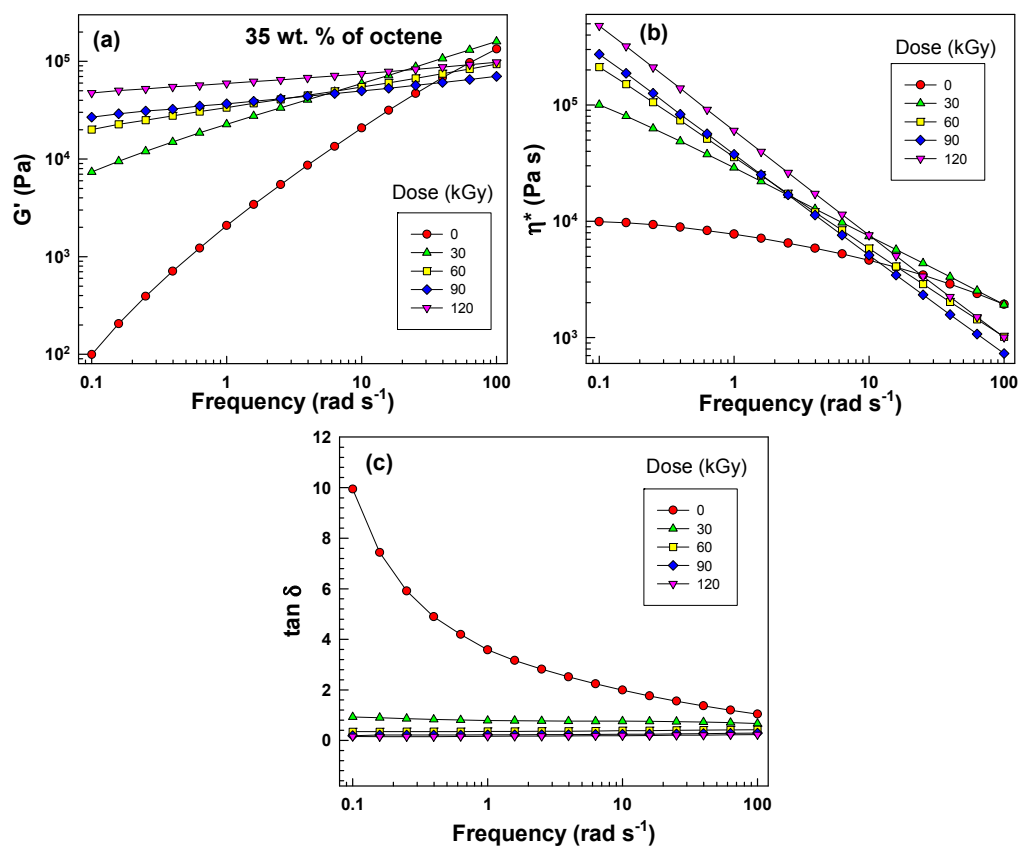

Figure 4. Rheology results at $150{ }^{\circ} \mathrm{C}$ for EOC-35 (a) $\mathrm{G}^{\prime},(\mathbf{b}) \eta^{*}$, (c) $\tan \delta$ as a function of frequency for variously irradiated samples.

The tan $\delta$ curves (see Figure 4c) exhibit a large difference for the radiation level in the range 0-60 kGy. Then, in the range 60-120 kGy, the differences in tan $\delta$ curves are smaller. Again, the largest difference one can observe for $\tan \delta$ values is especially at low frequencies; e.g., at $0.1 \mathrm{rad} \cdot \mathrm{s}^{-1}$ the $\tan \delta$ dropped from 10 to 1 just by $30 \mathrm{kGy}$ of irradiation.

The influence of octene content on the rheology data can be clearly seen on tan $\delta$ curves (see Figure 5). Figure 5a illustrates $\tan \delta$ curves as a function of frequency for the two copolymers before irradiation. The $\tan \delta$ curves are very similar. This corresponds well with the molecular weight data listed in Table 1 and the same original MFI being $3 \mathrm{~g} / 10 \mathrm{~min}$. Due to the extremely similar rheology and molecular weight data before irradiation, one can be certain that the conclusions made after irradiation are sound.

Figure $5 \mathrm{~b}$ shows the $\tan \delta$ curves after irradiation to $120 \mathrm{kGy}$. Clearly the EOC-35 with double branching density exhibits much lower $\tan \delta\left(0.15 \mathrm{vs} .0 .35\right.$ at $\left.0.1 \mathrm{rad} \cdot \mathrm{s}^{-1}\right)$. Lower $\tan \delta$ values correspond to better elastic behaviour (or better crosslinking).

To support the rheology data, we have carried out an additional high-temperature test, creep at $150{ }^{\circ} \mathrm{C}$. The results are shown in Figure 6a. In the initial time period of approximately $300 \mathrm{~s}$ the creep curves are almost exactly the same, whereas in the time period 300-1200 s the difference is much more pronounced. Clearly EOC-35 with higher branching density creeps less than EOC-20. The difference in absolute values for various times is more visible in Figure $6 \mathrm{~b}$. Higher octene content decreases creep at $150^{\circ} \mathrm{C}$. 
To support the previously shown data, we have carried out an analysis of insoluble gel content after boiling in xylene in a cage for a period of $6 \mathrm{~h}$. For this test only, we also used a low density polyethylene (LDPE). For simplicity we can assume that there are no short chain branches (SCB) ( 0 wt \% of octene) in LDPE. The results are depicted in Figure 7a. Samples before irradiation and samples irradiated to $30 \mathrm{kGy}$ dissolved completely. The differences among samples are better visible for 90 and $120 \mathrm{kGy}$. The data were analysed in detail according to the Charlesby-Pinner equation (shown in the following section).
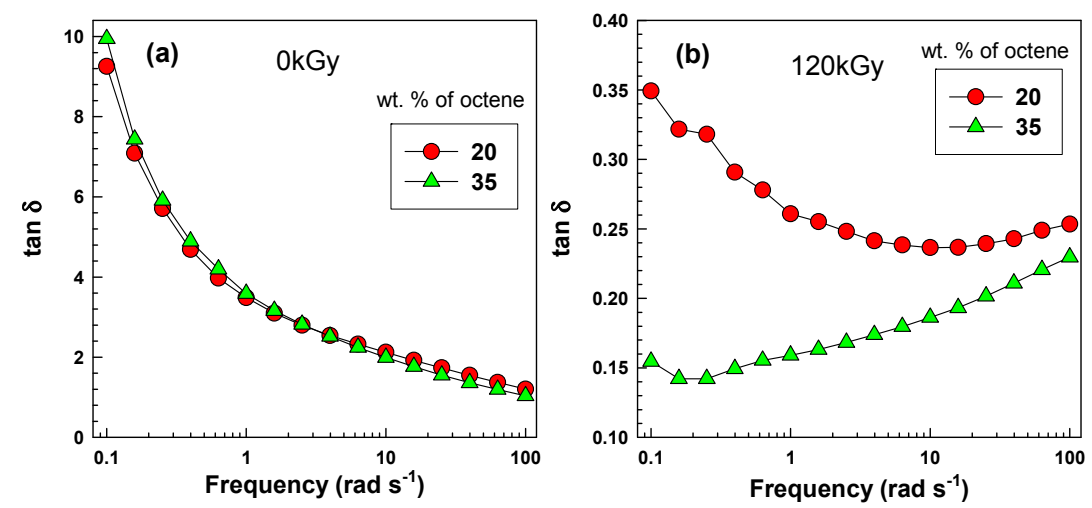

Figure 5. Rheology results (tan $\delta$ as a function of frequency) at $150{ }^{\circ} \mathrm{C}$ for EOC-20 and EOC-35. (a) 0 kGy, (b) $120 \mathrm{kGy}$.
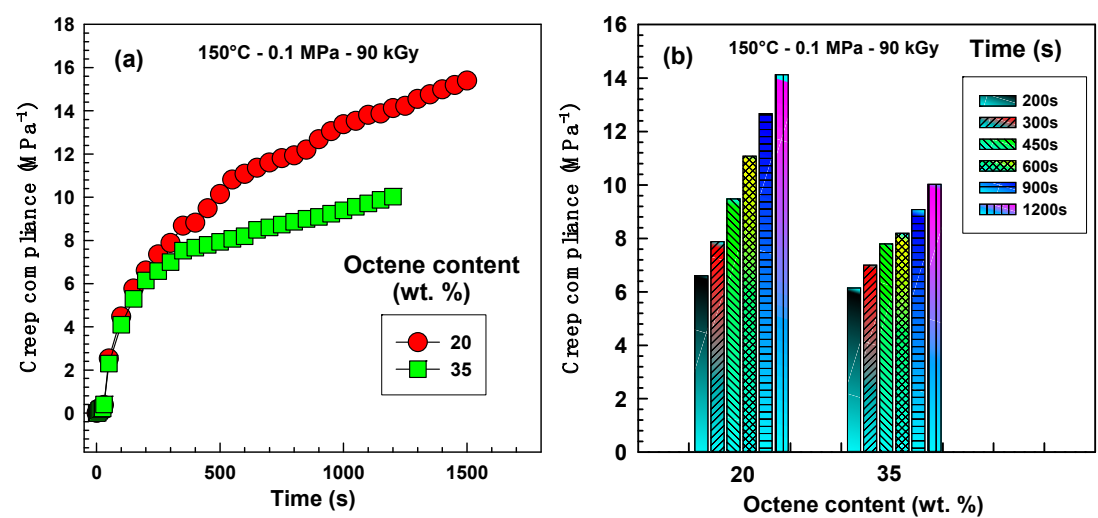

Figure 6. Creep behaviour at $150{ }^{\circ} \mathrm{C}$ at a stress of $0.1 \mathrm{MPa}$ for EOC-20 and EOC-35 irradiated by 90 kGy. (a) As a function of time; (b) as a function of octene content.
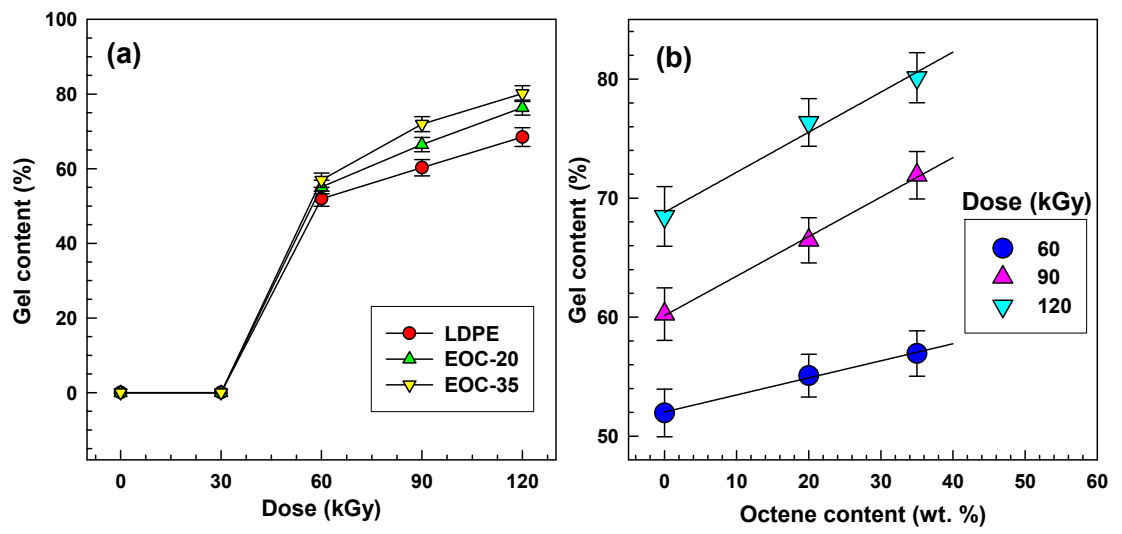

Figure 7. Gel content results for LDPE, EOC-20, EOC-35 (a) as a function of radiation level; (b) as a function of octene content. 


\section{Estimation of $G$ Values of Crosslinking by the Charlesby-Pinner Method}

Charlesby and Pinner published research results in 1959 concerning solubility of irradiated polyethylene. They analysed the data with the help of the following equation [30]:

$$
s+\sqrt{s}=\frac{p_{0}}{q_{0}}+\frac{1}{q_{0} u_{1} r}
$$

where $s$ is the sol fraction $(s+g=1), g$ is the gel fraction, $r$ is the radiation dose, $p_{0}$ is the fracture density per unit dose, $q_{0}$ is the density of crosslinked units per unit dose, $u_{1}$ is the number-average degree of polymerization.

These days the same equation is frequently expressed as [31]:

$$
s+\sqrt{s}=\frac{p_{0}}{q_{0}}+\frac{1}{q_{0} P_{n} D}
$$

where $P_{n}$ is the initial number-averaged degree of polymerization and $D$ is the absorbed radiation dose in kGy [32].

Many radiation-induced chemical changes are measured quantitatively in terms of a $G$ value, this being the number of such changes produced per $100 \mathrm{eV}$ absorbed in the system [30]. G values for crosslinking and chain scission are expressed as $G(X)$ and $G(S)$, respectively. Crosslinking and chain scission are two competing processes that always co-exist under radiation. The overall effect depends on which of the two is predominant at a certain time. Whenever $G(X)$ is larger than $G(S)$, the overall result is crosslinking, and whenever $G(S)$ is larger than $G(X)$, the overall result is degradation. Charlesby and Pinner equation containing $G$ values is expressed as [33]:

$$
s+\sqrt{s}=\frac{G(S)}{2 G(X)}+\frac{4.82 \times 10^{6}}{G(X) M_{n} D}
$$

where $M_{n}$ is the number-averaged molecular weight.

Turgis et al. used a modified version of this equation for copolymers AB [34]:

$$
s+\sqrt{s}=\frac{G(S)}{2 G(X)}+\frac{9.65 \cdot 10^{6} \cdot m_{A}}{G(X) \cdot D \cdot M_{w} \cdot\left[x_{B} \cdot m_{B}+\left(1-x_{B}\right) \cdot m_{A}\right]}
$$

where $m_{A}$ and $m_{B}$ are molecular weights of comonomer units $\mathrm{A}$ and $\mathrm{B}$, respectively. $x_{B}$ is the molar fraction of comonomer B.

The solubility of the two ethylene-octene copolymers was initially analysed with the help of Equation (2) (see Figure 8a). This led to intercept values $p_{0} / q_{0}$ (scission-to-crosslinking ratio) and slope values being $1 / q_{0} P_{n}$. More detailed analysis, shown in the Supplementary Material, then led also to other values: $q_{0}, p_{0}, G(X) / G(S), G(X)$, and $G(S)$. Comparison of these values is illustrated in Figure 9.

The density of crosslinked units per unit dose $\left(q_{0}\right)$ is quite similar for both copolymers. However, the fracture density per unit dose $\left(p_{0}\right)$ is quite different-it is considerably lower for EOC-35. Reduced scission then leads to a much higher crosslinking-to-scission ratio $(G(X) / G(S))$ for the copolymer with higher octene content. With a higher content of octene pendants, the probability of radical formation on octene pendants increases, and thus the main chain is attacked less. The mobility of the octene pendants is much higher (compared to main chain mobility) so that the radicals on octene have a higher probability of recombination with other free radicals, which leads to crosslinking. The situation is schematically shown in Figure 10. The free radical can lead to crosslinking or scission. A copolymer with higher octene content has more short chain branches, and thus the probability of radical formation on the branch is higher (see Figure 10a-free radical formation on octene pendant—options $\mathbf{c}$, d). While scission on the main chain (see Figure 10a—free 
radical formation on main chain-options $\mathbf{a}, \mathbf{b}$ ) leads to a decreased molecular weight, scission on an octene pendant has almost no influence at all on the molecular weight.
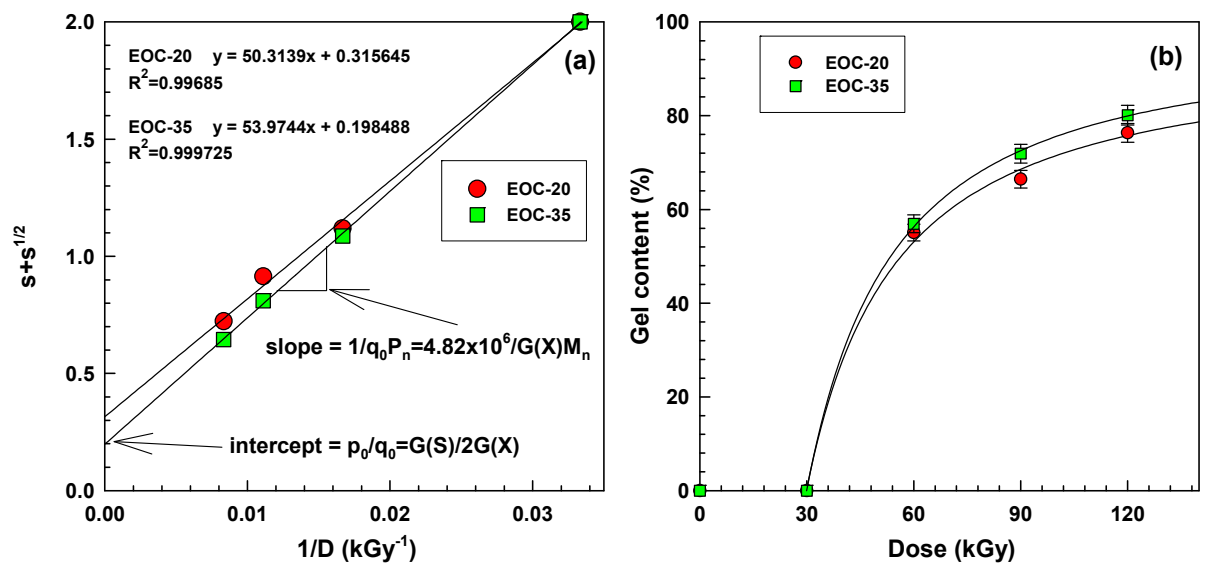

Figure 8. Charlesby-Pinner analysis for EOC-20 and EOC-35 (a) linear version, (b) non-linear curves according to Equation (7) in Supplementary Material.

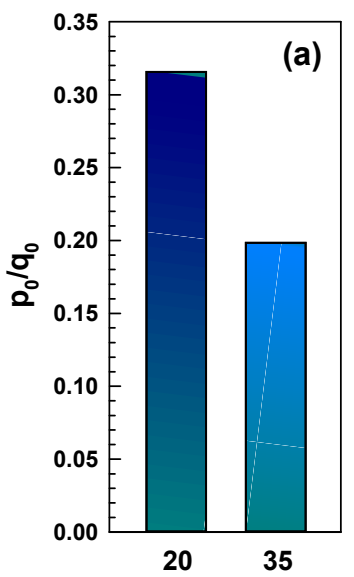

Octene cont. (wt. \%)

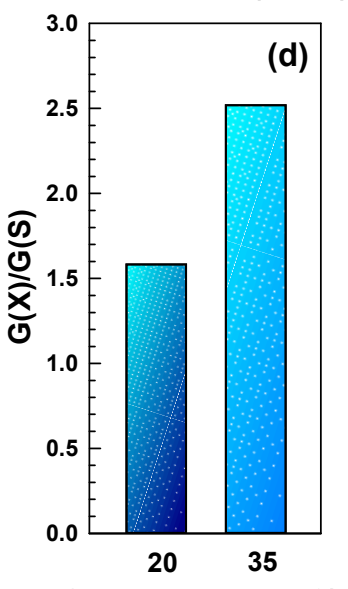

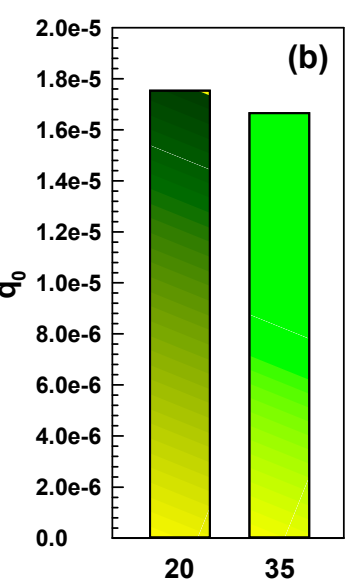

Octene cont. (wt. \%)

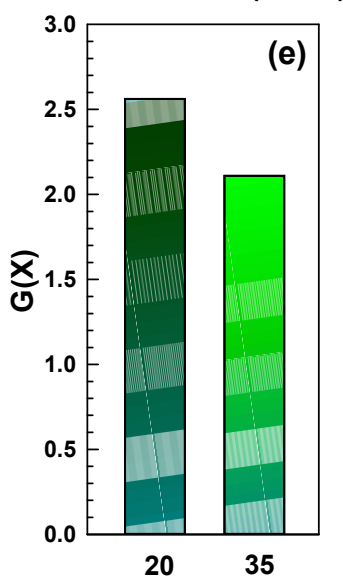

Octene cont. (wt. \%)

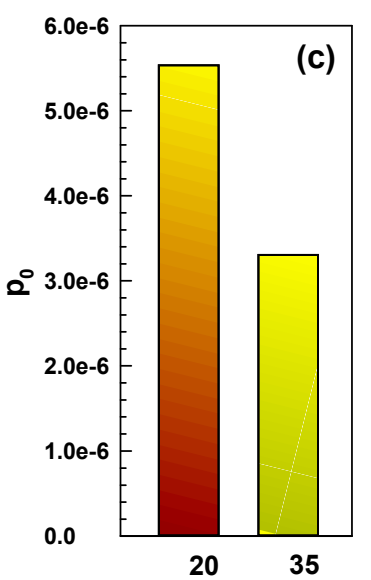

Octene cont. (wt. \%)

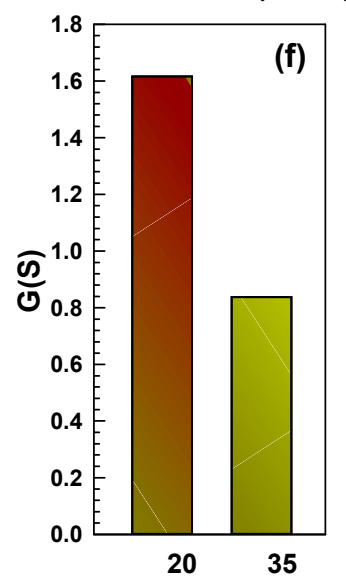

Octene cont. (wt. \%)

Figure 9. Charlesby-Pinner analysis for EOC-20 and EOC-35-continuation: (a) $p_{0} / q_{0}$, (b) $q_{0}$, (c) $p_{0}$, (d) $G(X) / G(S),(\mathbf{e}) G(X),(\mathbf{f}) G(S)$. $p_{0}$ is the fracture density per unit dose, $q_{0}$ is the density of crosslinked units per unit dose, $G$ values for crosslinking and chain scission are expressed as $G(X)$ and $G(S)$, and $G(X) / G(S)$ is the crosslinking-to-scission ratio. 
Another important fact is that a copolymer with a higher octene content contains a higher number of tertiary carbon atoms. After being exposed to e-beam radiation, the hydrogen atoms are extracted from carbon atoms. The radical on a tertiary carbon atom can be created more easily, even though the radicals on a main chain or on an octene branch are also generated (LDPE was also crosslinked, but to a lower extent). The polymer radicals can then form a crosslink by recombination with another polymer radical or they can extract a hydrogen atom from the neighbouring chain. Crosslinking options in Figure $10 \mathbf{b}, \mathbf{b}-\mathbf{b}, \mathbf{b}-\mathbf{d}, \mathbf{a}-\mathbf{b}, \mathbf{b}-\mathbf{c}$ play an important role during electron beam crosslinking of ethylene-octene copolymers. As it was shown, LDPE also crosslinks (a-a option) but to a lesser extent. Solubility results agree well with previously shown rheology and creep results.

(a) Free radical formation options

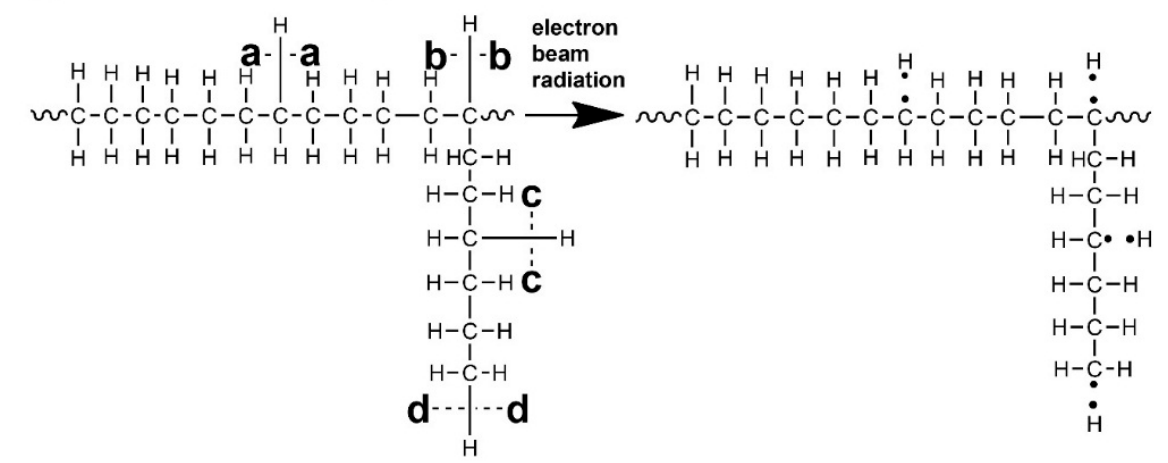

(b) Various crosslinking options

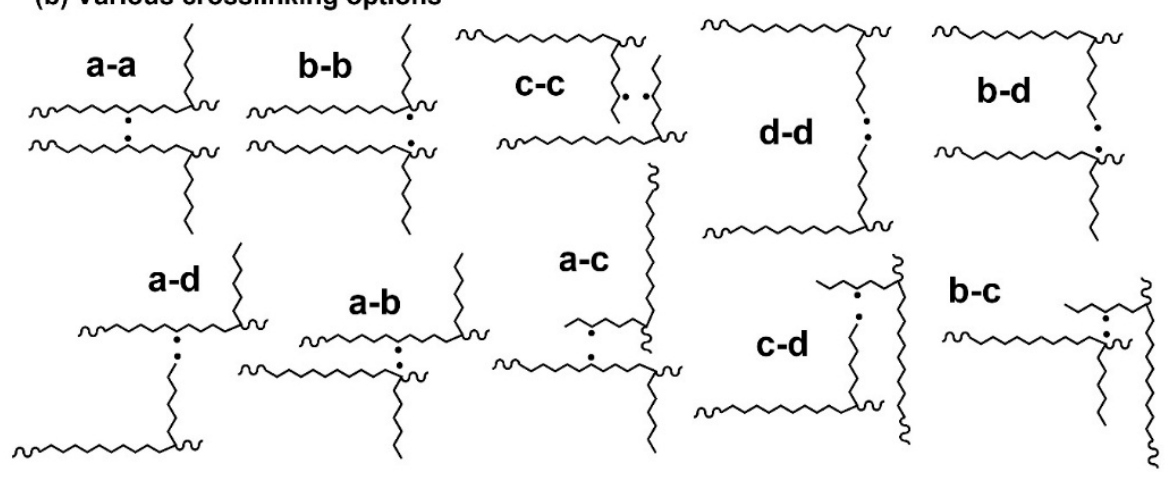

Figure 10. Schematic representation of (a) free radical formation options; (b) various crosslinking options.

These presented results correspond well with other researchers [8,9,18,35]. For example, Liu et al. investigated UV photodegradation of polyethylene compared to ethylene-octene copolymers with an increasing octene content of 20,30, and $38 \mathrm{wt} \%$. After $200 \mathrm{~h}$ of UV exposure the values of gel content for LDPE, EOC-20, EOC-30, and EOC-38 were 18\%, 22\%, 31\%, and $41 \%$, respectively [35].

Vachon et al. [9] investigated foaming behaviour of gamma-irradiated ethylene-octene copolymers (EOC) with the same melt flow index (MFI $=1 \mathrm{~g} / 10 \mathrm{~min}$ ) but different octene content, EOC-30 (Engage 8003) and EOC-38 (Engage 8100). After irradiation to $50 \mathrm{kGy}$ the copolymer with a higher octene content (EOC-38) exhibited an $80 \%$ gel content while the one with the lower octene content (EOC-30) had only a $68 \%$ gel content.

Abe et al. [8] made foam from two ethylene-1-hexene copolymers; LL1 had 25 branches and LL2 had 7 branches per 1000 backbone carbon atoms with the same molecular weight, $M_{\mathrm{n}}=4.6 \times 10^{4} \mathrm{~g} / \mathrm{mol}$. The foams were produced directly by moulding using $0.1-0.9 \mathrm{wt} \%$ of dicumylperoxide (DCP) and 8 phr of a blowing agent. The copolymer with a higher branching density (LL1) rendered a foam with a higher storage modulus $\mathrm{G}^{\prime}$, lower $\tan \delta$, and with a higher gel content. 
Sirisinha et al. [18] did research on silane-crosslinked EOC (Engage 8003) in comparison with LDPE. LDPE had a lower crosslinking rate and a lower gel content compared to EOC. In their case the short chain branching improved crosslinkability by using the silane method.

\section{Conclusions}

DMA testing revealed a large influence of octene content on storage modulus and $T_{\mathrm{g}}$, but a smaller influence of irradiation on properties below $T_{\mathrm{m}}$.

Rheology at $150{ }^{\circ} \mathrm{C}$ highlighted the huge differences in crosslinked polymers, especially in the 0-60 kGy range and at small frequencies $(0.1-1 \mathrm{~Hz})$. Before irradiation the two copolymers had very similar $\tan \delta$ curves, while after irradiation to $120 \mathrm{kGy}$ the EOC-35 had considerably lower $\tan \delta$ than EOC-20, which corresponds to better elasticity (or a higher level of crosslinking).

High-temperature creep test, especially after $300 \mathrm{~s}$, showed a considerably lower creep for EOC-35, confirming a higher level of crosslinking.

Analysis of insoluble gel content illustrated higher values for EOC-35, again confirming a higher level of crosslinking. Analysis according to the Charlesby-Pinner equation revealed increased crosslinking-to-scission ratio, $G(X) / G(S)$, for EOC-35. Interesting was a substantial decrease in the $\mathrm{G}(\mathrm{S})$ parameter. This was explained by scission on an octene pendant which does not lead to a scission of the main chain (and EOC-35 has more octene pendants). Also, in EOC-35 the amount of tertiary carbon atoms with higher reactivity is higher.

Supplementary Materials: The supplementary materials is available online at: www.mdpi.com/2073-4360/ 7/12/1530/s1.

Acknowledgements: This work has been supported by the Internal Grant Agency of the Tomas Bata University in Zlin. Number IGA/FT/2015/007.

Conflicts of Interest: The author declares no conflict of interest. The founding sponsors had no role in the design of the study; in the collection, analyses, or interpretation of data; in the writing of the manuscript, and in the decision to publish the results.

\section{References}

1. Chum, P.S.; Kao, C.I.; Knight, G.W. Structure-property relationships in polyolefins made by constrained geometry catalyst technology. Plast. Eng. 1995, 51, 21-23.

2. Alamo, R.G.; Viers, B.D.; Mandelkern, L. Phase-structure of random ethylene copolymers-A study of counit content and molecular-weight as independent variables. Macromolecules 1993, 26, 5740-5747. [CrossRef]

3. Bensason, S.; Minick, J.; Moet, A.; Chum, S.; Hiltner, A.; Baer, E. Classification of homogeneous ethylene-octene copolymers based on comonomer content. J. Polym. Sci. B Polym. Phys. 1996, 34, 1301-1315. [CrossRef]

4. Wood-Adams, P.M.; Dealy, J.M.; Degroot, A.W.; Redwine, O.D. Effect of molecular structure on the linear viscoelastic behavior of polyethylene. Macromolecules 2000, 33, 7489-7499. [CrossRef]

5. Minick, J.; Moet, A.; Hiltner, A.; Baer, E.; Chum, S.P. Crystallization of very-low-density copolymers of ethylene with $\alpha$-olefins. J. Appl. Polym. Sci. 1995, 58, 1371-1384. [CrossRef]

6. Casey, P.; Chen, H.Y.; Poon, B.; Bensason, S.; Menning, B.; Liu, L.Z.; Hu, Y.S.; Hoenig, W.; Gelfer, M.; Dems, B.; et al. Polyolefin based crosslinked elastic fiber: A technical review of DOW XLA ${ }^{\mathrm{TM}}$ elastic fiber technology. Polym. Rev. 2008, 48, 302-316. [CrossRef]

7. Li, J.Q.; Peng, J.; Qiao, J.L.; Jin, D.B.; Wei, G.S. Effect of gamma Irradiation on ethylene-octene copolymers. Radiat. Phys. Chem. 2002, 63, 501-504. [CrossRef]

8. Abe, S.; Yamaguchi, M. Study on the Foaming of crosslinked polyethylene. J. Appl. Polym. Sci. 2001, 79, 2146-2155. [CrossRef]

9. Vachon, C.; Gendron, R. Effect of gamma-irradiation on the foaming behavior of ethylene-co-octene polymers. Radiat. Phys. Chem. 2003, 66, 415-425. [CrossRef] 
10. Kale, L.T.; Plumley, T.A.; Patel, R.M.; Redwine, O.D.; Jain, P. Structure-property relationships of ethylene/1-octene and ethylene/1-butene copolymers made using insite technology. J. Plast. Film Sheeting 1996, 12, 27-40.

11. Nicolas, J.; Ressia, J.A.; Valles, E.M.; Merino, J.C.; Pastor, J.M. Characterization of metallocene ethylene-1-octene copolymers with high comonomer content cross-linked by dicumyl peroxide or $\beta$-radiation. J. Appl. Polym. Sci. 2009, 112, 2691-2700. [CrossRef]

12. Sirisinha, K.; Meksawat, D. Comparison in processability and mechanical and thermal properties of ethylene-octene copolymer crosslinked by different techniques. J. Appl. Polym. Sci. 2004, 93, 1179-1185. [CrossRef]

13. Sirisinha, K.; Meksawat, D. Changes in properties of silane-water crosslinked metallocene ethylene-octene copolymer after prolonged crosslinking time. J. Appl. Polym. Sci. 2004, 93, 901-906. [CrossRef]

14. Jiao, C.M.; Wang, Z.Z.; Gui, Z.; Hu, Y. Silane grafting and crosslinking of ethylene-octene copolymer. Eur. Polym. J. 2005, 41, 1204-1211. [CrossRef]

15. Sirisinha, K.; Meksawat, D. Preparation and properties of metallocene ethylene copolymer crosslinked by vinyltrimethoxysilane. Polym. Int. 2005, 54, 1014-1020. [CrossRef]

16. Sirisinha, K.; Chimdist, S. Comparison of techniques for determining crosslinking in silane-water crosslinked materials. Polym. Test 2006, 25, 518-526. [CrossRef]

17. Kamphunthong, W.; Sirisinha, K. Structure development and viscoelastic properties in silane-crosslinked ethylene-octene copolymer. J. Appl. Polym. Sci. 2008, 109, 2347-2353. [CrossRef]

18. Sirisinha, K.; Chimdist, S. Silane-crosslinked ethylene-octene copolymer blends: thermal aging and crystallization study. J. Appl. Polym. Sci. 2008, 109, 2522-2528. [CrossRef]

19. Sirisinha, K.; Kamphunthong, W. Rheological analysis as a means for determining the silane crosslink network structure and content in crosslinked polymer composites. Polym. Test 2009, 28, 636-641. [CrossRef]

20. Bailly, M.; Kontopoulou, M.; El Mabrouk, K. Effect of polymer/filler interactions on the structure and rheological properties of ethylene-octene copolymer/nanosilica composites. Polymer 2010, 51, 5506-5515. [CrossRef]

21. Garnier, L.; Duquesne, S.; Casetta, M.; Lewandowski, M.; Bourbigot, S. Melt spinning of silane-water cross-linked polyethylene-octene through a reactive extrusion process. React. Funct. Polym. 2010, 70, 775-783. [CrossRef]

22. Kamphunthong, W.; Sirisinha, K. Thermal property improvement of ethylene-octene copolymer through the combined introduction of filler and silane crosslink. J. Appl. Polym. Sci. 2010, 115, 424-430. [CrossRef]

23. Sirisinha, K.; Boonkongkaew, M.; Kositchaiyong, S. The effect of silane carriers on silane grafting of high-density polyethylene and properties of crosslinked products. Polym. Test 2010, 29, 958-965. [CrossRef]

24. Chen, W.C.; Lai, S.M.; Qiu, R.Y.; Tang, S.X. Role of silane crosslinking on the properties of melt blended metallocene polyethylene- $g$-silane/clay nanocomposites at various clay contents. J. Appl. Polym. Sci. 2012, 124, 2669-2681. [CrossRef]

25. Nordin, R.; Ismail, H.; Ahmad, Z.; Rashid, A. Performance improvement of (linear low-density polyethylene)/poly(vinyl alcohol) blends by in situ silane crosslinking. J. Vinyl Addit. Technol. 2012, 18, 120-128. [CrossRef]

26. Sirisinha, K.; Boonkongkaew, M. Improved silane grafting of high-density polyethylene in the melt by using a binary initiator and the properties of silane-crosslinked products. J. Polym. Res. 2013, 20, 9. [CrossRef]

27. Perraud, S.; Vallat, M.F.; Kuczynski, J. Radiation crosslinking of poly(ethylene-co-octene) with electron beam radiation. Macromol. Mater. Eng. 2003, 288, 117-123. [CrossRef]

28. Mishra, J.K.; Chang, Y.W.; Lee, B.C.; Ryu, S.H. Mechanical properties and heat shrinkability of electron beam crosslinked polyethylene-octene copolymer. Radiat. Phys. Chem. 2008, 77, 675-679. [CrossRef]

29. Benson, R.S.; Moore, E.A.; Martinez-Pardo, M.E.; Zaragoza, D.L. Effect of gamma irradiation on ethylene-octene copolymers produced by constrained geometry catalyst. Nucl. Instrum. Meth. B 1999, 151, 174-180. [CrossRef]

30. Charlesby, A.; Pinner, S.H. Analysis of the solubility behaviour of irradiated polyethylene and other polymers. Proc. R. Soc. Lon. Ser. A 1959, 249, 367-386. [CrossRef]

31. Dubey, K.A.; Chaudhari, C.V.; Rao, R.; Bhardwaj, Y.K.; Goel, N.K.; Sabharwal, S. Radiation processing and characterization of poly(vinyl alcohol) nano-composites, part 1: Nano-particulate filler tuned crosslinking behavior. J. Appl. Polym. Sci. 2010, 118, 3490-3498. [CrossRef] 
32. Mondal, M.; Gohs, U.; Wagenknecht, U.; Heinrich, G. Efficiency of high energy electrons to produce polypropylene/natural rubber-based thermoplastic elastomer. Polym. Eng. Sci. 2013, 53, 1696-1705. [CrossRef]

33. Makuuchi, K.; Cheng, S. Radiation Processing Of Polymer Materilas And Its Industrial Applications; Wiley: New York, NY, USA, 2012.

34. Turgis, J.D.; Coqueret, X. Electron beam sensitivity of butyl acrylate copolymers: effects of composition on reactivity. Macromol. Chem. Phys. 1999, 200, 652-660. [CrossRef]

35. Liu, Z.Y.; Chen, S.J.; Zhang, J. Photodegradation of ethylene-octene copolymers with different octene contents. Polym. Degrad. Stab. 2011, 96, 1961-1972. [CrossRef]

(C) 2015 by the author; licensee MDPI, Basel, Switzerland. This article is an open access article distributed under the terms and conditions of the Creative Commons by Attribution (CC-BY) license (http://creativecommons.org/licenses/by/4.0/). 